\title{
Are books too expensive?
}

We love books not merely for what's in them. Books feel good, even smell good. Touching them, we rub the grain of their bindings, we skate our fingers across fine paper, we run our thumbs through pages as if they were guitar strings. They feel good whether they are words by Flaubert or encyclopaedias of pharmacology.

In a bookshop, we can rest our arm on a shelf lost in the art of Chinese porcelains as we face a stack of paperback jackets glowing with sex. We may dash into the shop to get out of the rain, and yet walk out with a storm of ideas, provoked by a chapter heading.

Until quite recently, perhaps our only regret, stimulated by an encounter with books in a bookshop, was the certainty that one life could never give us enough time to read all the books worth reading. There once was a time we could pay our bill and walk out into the street with a few titles under our arm, all for the price of the lunch skipped that afternoon.

Today, of course, the prices confound the pleasures of buying books. What we once could purchase for the price of a skipped lunch, now costs us the equivalent of a dinner in a first-class restaurant. And when we get the bill for scholarly books the tally looks like what we might have expected to spend for a meal in a great French restaurant.

Book reviewers for this periodical of ten complain about the high prices. Young scientists despair at ever being able to afford them. And the rest of us grumble, often attributing the prices to the greed of publishers. What is to be done? Some argue that if publishers of scientific and technical books showed some restraint, restricting the number of symposia or limiting the output of House titles which are of interest only to narrow specialists, then prices would fall. According to this claim the prices of scholarly books are inversely proportional to the population served. Consequently, publishers must chose books for larger audiences.

There are those who suggest that the best way of lowering the prices of scholarly books is to eliminate unnecessary duplication of titles. Take, for example, the book displays at the Federation of American Societies for Experimental Biology meeting in California a week ago, where more than two dozen publishers exhibited their books. Biologists interested in a book on, let us say, interferon, could choose from among five or six new volumes on the subject, each one from a different publisher along the aisle. We would turn fewer trees to pulp and prices would fall if only a single publisher issued a book on each topic, or so this argument goes.
The difficulty with all these solutions is that the regulation of the science book publishing industry would be much like regulating science itself. Scientific literature rides the caboose on the train of science. Where science goes, publishers inevitably follow.

In order to make any of these proposals work, we will require men and women of great vision. They will need, for example, to choose from among the hundreds of symposia held each year those which should be privileged to appear in print. They will need to determine which are destined to be the classics, to be used in classrooms and laboratories over the next decade, and which should end with the afterdinner speech at the closing banquet.

Or consider those books which might never have been published had someone thought them too specialized. Who among us has the power to predict which area of investigation, now at the periphery of science, will some day emerge at the core?

And as for the proliferation of similar titles on the same subject: can any of us pick the author who will write the best book?

It is true that the rain of books falls most heavily on the libraries. With each slash of the budget, librarians can afford to buy fewer books. As libraries, traditionally the principal customers for scholarly publications, purchase still fewer titles, publishers are forced to charge yet higher prices. And so with each twist of the inflationary spiral, libraries and publishers alike struggle to breathe.

Yet neither inflation nor the ineluctable way in which science unfolds offers absolution to the publishers. We all recognize those who maintain their dignity, even under the strain of conflicting market forces, by their good books. There are those publishers, however, who acknowledge that in order to feed their hungry publishing mill, they must grind out lots of books - good or bad, it hardly makes any difference. Some publishers don't even blush when they compare their own books with sausages or shoelaces.

When will it all end? When will we able to walk into our local bookshop again, pull a volume off the shelf, and pay the bill without anxiety? For the moment the outlook in grim and will remain so at least until the pace of worldwide inflation slackens. Publishers are not immune to the rapid rise in costs experienced nearly everywhere. Paper, binding, typesetting, distribution and advertising costs are likely to scramble to still higher peaks as costs climb generally.

When we learn how to control an economy gone beserk, we may learn how to control the prices of books. 